\title{
Depression Affects Working Memory Performance: A Functional Near Infrared Spectroscopy (fNIRS) \\ Study*
}

\section{Özge Vural ( $\nabla$ vurallozge@gmail.com )}

Istanbul Medipol University: Istanbul Medipol Universitesi https://orcid.org/0000-0003-1932-960X

Erol Yıldırım

Istanbul Medipol University: Istanbul Medipol Universitesi

\section{Research Article}

Keywords: BDI, Depression, n-back, NIRS, PFC

Posted Date: December 10th, 2021

DOI: https://doi.org/10.21203/rs.3.rs-1091665/v1

License: (c) (i) This work is licensed under a Creative Commons Attribution 4.0 International License. Read Full License 


\section{Abstract}

Depression is a complex disorder that can be caused by psychosocial and biological conditions and it not only effects mood disorders, but also cognitive functions such as memory, decision making, psychomotor speed and attention. As a result of the studies, some findings indicate that depressed individuals perform worse in neuropsychological tests than healthy individuals, while other studies indicate there is no difference between the two groups. According to neuroimaging studies on this subject, functional and anatomical differences were detected at the cortex and subcortical levels in the prefrontal lobe. This study is consisting of two parts, behavioral and neuroimaging using fNIRS. BDI was applied to the participants. The average age of the group with lower BDI score is $23,9 \pm 3,04$; the average age of the higher group with higher BDI score is 22,2+2,28. A visuospatial 2-back task, which includes 4 different stimulus types with neutral, emotional, verbal, and non-verbal qualities, was applied to the participants. No significant differences were observed between the two groups in behavioral data. However, when fNIRS results were examined, it was found that the group with the high BDI scores showed more activation in the right PFC during the visuospatial 2-back task compared to the group with low BDI scores. Although the fNIRS results are consistent in the literature, behavioral findings support some of the findings in literature, while contradicting others. It is thought that the reason for this may be that participants are young, and the 2back task is not difficult enough.

\section{Introduction}

Depression affects some cognitive functions such as attention, memory, learning, and decision making, although this disorder is included within the category of mood disorders in the DSM-5 (1-4). Cognitive disorders observed in depression are difficulties in making decisions due to slowing down of the thought system and tendency to negative thoughts, memory impairment increases with the severity of depression, delusions that may lead to suicide due to mood disorders and attention disorders (2).

In depression, anatomical and functional changes are also observed in the brain (5). Although attention, memory and executive functions have been shown to be negatively affected $(3,4,6)$, some studies have not found any abnormal results regarding these cognitive processes, but neuroimaging findings have been shown to indicate a difference in neural activity (7). These abnormalities were seen in the prefrontal cortex (PFC) and in subcortical structures such as some regions of the striatum, amygdala, and thalamus (8).

A study published in 2016 applied a neuropsychological test battery to people diagnosed with major depressive disorder to examine the relationship between the severity of major depression symptoms and subjective memory complaints, and showed that the scores of patients with depressive disorder were significantly lower than the healthy controls (9). It has been reported that people with high depression scores have low scores in some functions specific to the right hemisphere (10).

According to the results of the NIRS study conducted by Liu et al., which deals with the differentiation in brain activity in depression, the oxyhemoglobin $(\mathrm{oxyH})$ ) changes were observed in bilateral PFC and anteromedial PFC in the MDD (11). 
In a review study, it is said that people with depression perform poorly in cognitive tests related to areas such as recognizing emotional faces, line direction, 3-D structure perception, spatial learning, pattern recognition, and it is shown that the severity of depression negatively affects these cognitive functions (10).

There are many neuroimaging studies examining working memory (WM) and brain connectivity. According to the neuroimaging studies, places that show increased activity in tasks related to WM include the posterior cingulate cortex and medial frontal areas, which are also parts of the resting state network (12). Studies provide evidence that the frontal cortex is associated with WM (12-16).

Research using NIRS has generally focused on verbal fluency, and publications on visuospatial WM are limited. In the verbal fluency experiment of Kawano et al. with functional near infrared spectroscopy (fNIRS), a negative correlation was observed between depression score and frontal lobe activity (17). In the study of Kinou et al., people with MDD showed reduced frontopolar PFC and DLPFC activity compared to the healthy controls (18). In an fNIRS study using the n-back task, it is stated that MDD patients show a decreased activation in the inferior prefrontal region compared to the healthy controls (19). In the visualspatial WM experiments of Schecklmann et al. using NIRS, groups with depressive features showed reduced PFC activity, ventrolateral and dorsolateral, compared to the healthy controls (20). In another study, although there was no behavioral difference between the MDD and the healthy control groups during the verbal fluency task, it was reported that there was hypoactivation in the left DLPFC as a result of brain imaging performed with NIRS in the MDD group (21). In another NIRS study, hypoactivation in the bilateral frontal cortex was observed in depressed individuals in the n-back task performed before the ECT application, and an increase in the bilateral frontal cortex activation was observed after the ECT application (22).

In addition to emotional problems, depressed individuals also experience cognitive impairments in the form of visuospatial WM impairment. Therefore, understanding the brain structures and processes that mediate these cognitive functions will facilitate the planning of cognitive rehabilitation based on neuromodulation.

With this study, it was desired to examine the effect of high depression symptoms on visuospatial WM performance, to examine the topographical representation of visuospatial WM in the PFC with fNIRS.

\section{Method}

\section{Study Center:}

The study was carried out in Istanbul Medipol University - South Campus- REMER-fINCAN Laboratory.

\section{Participants:}

The research was conducted with 501 people, who were university students/graduates, aged between 18-35 and volunteered to participate in the study, which were easily reached through sampling, and among these people, a total of 62 individuals with the highest and lowest scores on the Beck Depression Scale were evaluated in terms of visual-spatial scores. Participated in the back experiment. Participants with a BDI 
score lower than 11 were accepted to the Low Depression Score group, and participants with a BDI score higher than 23 were accepted to the High Depression Score group. Hemodynamic response records were recorded using NIRS from 62 people who participated in the visuospatial 2-back experiments, 23 people with low depression scores and 11 people with high depression scores. In the fNIRS analysis, the groups were balanced according to age and education information, and were formed randomly, with 11 people in each group.

Participants who received appropriate scores from the BDI and had a neuropsychiatric diagnosis in the past or still, and those who received psychotherapy or medical treatment for psychiatric diseases in the last 6 months were not included in the experiments.

\section{Experimental Procedure}

\section{Beck Depression Inventory (BDI)}

It is a 21-item scale applied based on self-report and used clinically for the diagnosis of depression. This scale was developed by Beck (23). This scale was adapted to Turkish in 1989 (24). In this study, 11 points or less were included in the Low Depression Score group, and 23 points and above were included in the High Depression Score group.

\section{State-Trait Anxiety Inventory}

A total of 40 self-reported and developed by Spielberg used to measure state or trait anxiety (25). 20 item "State Anxiety Inventory" section of this scale was used. This scale was adapted into Turkish in 1983 (26).

\section{Working Memory Experiment}

The purpose-tailored n-back task (27) was used in the research via stimulus presentation software e-Prime (28). In this study, the 2-back paradigm was used and a series of sequential stimuli was presented to the participant and the participant was expected to decide whether the last stimulus was "in the same place" as the two previous stimuli (29).

In the study, the visuospatial 2-back task was applied using stimuli with emotional and neutral content:

1. The 2-back paradigm using the human face: In this study used the 2-back task adapted from Vermeij et al. used in their study (30). Faces with emotion expression were used in the emotional load condition, and neutral faces were used in the neutral stimulus condition. In total, there are 2 different blocks containing a human face. The facial images used were selected from KDEF (31).

2. The 2-back paradigm using words: Emotionally loaded in the emotional load condition and neutral words in the neutral condition are shown, similar to the presentation style of visual stimuli. Information on the arousal and valence of the words, as well as neutral words and emotion-containing words (32) are presented in Table 1. 
Table 1

Information about the verbal stimuli used in the experiment and their arousal and valence

\begin{tabular}{|llll|}
\hline Words & Emotion & Valence & Arousal \\
\hline Friend & Positive & 8,21 & 6,65 \\
\hline Delight & Positive & 8,18 & 6,13 \\
\hline Smile & Positive & 8,19 & 6,75 \\
\hline Peace & Positive & 8,03 & 6,38 \\
\hline Vacation & Positive & 7,78 & 6,38 \\
\hline Bomb & Negative & 3,73 & 7,94 \\
\hline Sadness & Negative & 3,95 & 5,89 \\
\hline Cruelty & Negative & 4,89 & 7,42 \\
\hline Mourning & Negative & 4,37 & 5,66 \\
\hline Slaughter & Negative & 4,35 & 6,32 \\
\hline Door & Neutral & 5,21 & 2,79 \\
\hline Letter & Neutral & 5,42 & 2,94 \\
\hline Clasp & Neutral & 5,38 & 3,14 \\
\hline Corner & Neutral & 5,14 & 3,22 \\
\hline Sample & Neutral & 5,25 & 3,28 \\
\hline
\end{tabular}

\section{NIRS (Near Infrared Spectroscopy)}

In the study, hemodynamic responses were measured with the NIRS device (NIRScout 8-16, NIRx Medizintechnik GmbH, Germany) available in the REMER-fiNCAN Laboratory. Measurements were made by placing the device's 15 optodes (8 source and 7 detector) in the right and left PFC areas, and 20 channels, 18 of which were symmetrical and 2 of which were in the midline. Optodes are placed in the slots in the elastic caps compatible with the international EEG 10/20 system, and the distance between the source and the detector is fixed at $3 \mathrm{~cm}$. NirSite 2021.4 program was used while creating this montage.

In this study, where data were collected by the block design method, there is a single block for each condition (neutral faces, neutral words, emotional faces, and emotional words). The recordings are in continuous wave form and the oxyHb and deoxy $\mathrm{Hb}$ concentration changes were monitored on the screen simultaneously with the experiment. This variation is calculated according to the modified Beer Lambert Law (33). The "detrend" process is applied to the baseline fluctuations in the continuous wave that continues throughout the recording with the recorder's own software. 


\section{Data Processing}

Hemodynamic brain activation during the 2-back task was recorded with the NirStar 15.3 software. The data to which the detrend process was applied during the recording were analyzed with the nirsLAB program. Noises created by heartbeat, pulse and unwanted movements in the NIRS data were eliminated by applying a band pass filter (0.01-0.2 Hz). The distance between channels was set as $3 \mathrm{~cm}$.

\section{Statistical Analysis}

After the determined parameters were applied to the hemodynamic data, the HRF graph was selected using the GLM at the SPM 1 level only for the oxyHb data, again via the interface of nirsLAB, for analysis at the individual level. ANOVA was used for analyzes at SPM 1 level. Independent groups t-test was used in the analyzes at SPM 2 level. Statistics on sociodemographic characteristics of individuals were calculated using Jamovi (34). Behavioral data were analyzed Mann Whitney-U. The significance level was determined as 0.05 for both behavioral data and NIRS data.

\section{Results}

\section{Behavioral Results}

BDI was applied to 501 people in total, and people with a BDI score below 11 were assigned to the group with a low BDI score, and people with a BDI score above 23 were assigned to the group with a high BDI score. The STAI State Anxiety Scale was applied to measure state anxiety before the participants in the experiment completed the exercise phase and before they started the visuospatial WM application. Descriptive statistics of the scales are presented in Table 2. 
Table 2

Descriptive statistics of BDI and STAI Form Scales

\begin{tabular}{|llllll|}
\hline \multirow{2}{*}{ N } & Groups & BDI & STAI Form & Education (year) & Age \\
\hline \multirow{2}{*}{ Mean } & Low BDI Score & 37 & 37 & 37 & 37 \\
\hline & High BDI Score & 25 & 25 & 25 & 25 \\
\hline Median & Low BDI Score & 5,43 & 30,7 & 16,8 & 23,9 \\
\hline \multirow{2}{*}{ Standard Deviation } & High BDI Score & 31,4 & 42,0 & 15,8 & 22,2 \\
\hline \multirow{2}{*}{ Minimum } & Low BDI Score & 6,00 & 31,0 & 17,0 & 24,0 \\
\hline \multirow{2}{*}{ Maximum } & High BDI Score & 32,0 & 42,0 & 16,0 & 22,0 \\
\hline & High BDI Score & 4,74 & 9,02 & 1,96 & 3,04 \\
\hline & Low BDI Score & 0,00 & 0,00 & 13,0 & 2,28 \\
\hline & High BDI Score & 23,0 & 21,0 & 12,0 & 19,0 \\
\hline
\end{tabular}

Behavioral findings based on the correct numbers obtained because of the visual spatial 2-back task are analyzed. Analysis results are presented in Table 3. We were unable to include some people in the analysis due to technical glitches. 
Table 3

Descriptive statistic of behavioral findings of groups separated by BDI score

\begin{tabular}{|c|c|c|c|c|c|c|c|}
\hline & Groups & $\begin{array}{l}\text { Neutral } \\
\text { Face }\end{array}$ & $\begin{array}{l}\text { Neutral } \\
\text { Words }\end{array}$ & $\begin{array}{l}\text { Emotional } \\
\text { Words }\end{array}$ & $\begin{array}{l}\text { Emotional } \\
\text { Face }\end{array}$ & $\begin{array}{l}\text { Emotional } \\
\text { Stimulus }\end{array}$ & $\begin{array}{l}\text { Neutral } \\
\text { Stimulus }\end{array}$ \\
\hline \multirow[t]{2}{*}{$N$} & $\begin{array}{l}\text { Low } \\
\text { BDI } \\
\text { Score }\end{array}$ & 23 & 23 & 23 & 23 & 23 & 23 \\
\hline & $\begin{array}{l}\text { High } \\
\text { BDI } \\
\text { Score }\end{array}$ & 20 & 20 & 20 & 20 & 20 & 20 \\
\hline \multirow[t]{2}{*}{ Mean } & $\begin{array}{l}\text { Low } \\
\text { BDI } \\
\text { Score }\end{array}$ & 29,4 & 26,6 & 30,6 & 30,0 & 60,6 & 56,0 \\
\hline & $\begin{array}{l}\text { High } \\
\text { BDI } \\
\text { Score }\end{array}$ & 29,9 & 27,9 & 29,9 & 31,2 & 61,1 & 57,8 \\
\hline \multirow[t]{2}{*}{ Median } & $\begin{array}{l}\text { Low } \\
\text { BDI } \\
\text { Score }\end{array}$ & 30,0 & 27,0 & 31,0 & 33,0 & 64,0 & 58,0 \\
\hline & $\begin{array}{l}\text { High } \\
\text { BDI } \\
\text { Score }\end{array}$ & 32,0 & 28,0 & 31,0 & 32,0 & 62,5 & 59,0 \\
\hline \multirow[t]{2}{*}{$\begin{array}{l}\text { Standard } \\
\text { Deviation }\end{array}$} & $\begin{array}{l}\text { Low } \\
\text { BDI } \\
\text { Score }\end{array}$ & 5,02 & 3,87 & 3,04 & 5,94 & 8,52 & 8,18 \\
\hline & $\begin{array}{l}\text { High } \\
\text { BDI } \\
\text { Score }\end{array}$ & 4,64 & 3,18 & 2,58 & 4,23 & 5,66 & 6,90 \\
\hline \multirow[t]{2}{*}{ Minimum } & $\begin{array}{l}\text { Low } \\
\text { BDI } \\
\text { Score }\end{array}$ & 19,0 & 18,0 & $24, .0$ & 16,0 & 42,0 & 39,0 \\
\hline & $\begin{array}{l}\text { High } \\
\text { BDI } \\
\text { Score }\end{array}$ & 21,0 & 17,0 & 23,0 & 22,0 & 45,0 & 38,0 \\
\hline \multirow[t]{2}{*}{ Maximum } & $\begin{array}{l}\text { Low } \\
\text { BDI } \\
\text { Score }\end{array}$ & 35,0 & 31,0 & 35,0 & 35,0 & 70,0 & 66,0 \\
\hline & $\begin{array}{l}\text { High } \\
\text { BDI } \\
\text { Score }\end{array}$ & 35,0 & 33,0 & 33,0 & 35,0 & 68,0 & 67,0 \\
\hline
\end{tabular}

The Mann Whitney-U test was used between the groups to show the significance results of the number of correct answers given according to the stimulus types. There was no behavioral difference between the groups with low BDI scores and high BDI scores $(\mathrm{p}<.05)$, and the groups showed the same success in the visuospatial 2-back task. 


\section{fNIRS Results}

Analyzes were made on whether the number of correct responses to stimuli differed between the groups. According to the independent groups t-test results, no significant difference was observed (Figure 3) between groups in the neutral face stimulus condition ( $p<.05)$, but a significant difference was observed between groups in channels 13, 14 and 18 in the emotional faces condition (Figure 4). The group with a high depression score showed higher activation in this condition than the control group.

According to fNIRS results of hemodynamic brain activity in the neutral word stimulus condition of the group with low BDI scores and high BDI scores, higher activation was observed in channels $12,13,14,18$ and 19 in the right frontal lobe compared to other channels, and participants with higher BDI scores were more active in these channels.

According to fNIRS results of hemodynamic brain activity in the emotional word condition of the group with low BDI scores and high BDI scores, higher activation was observed in channels 14 and 18 in the right frontal lobe compared to other channels, and participants with higher BDI scores showed more activation in these channels.

Apart from these analyses, the presented stimuli were also analyzed as emotional and neutral stimuli. As a result of the independent sample t-test performed between groups with low BDI scores and high BDI scores, higher activation was observed in channels 14 and 18 in the right frontal lobe in the group with high BDI scores in both neutral stimuli and emotional stimuli conditions compared to the control group.

\section{Discussion}

The primary aim of this study is to investigate whether there will be a difference between behavioral and brain hemodynamic responses during the visual-spatial WM task in groups with low and high depression scores, although there is no clinical diagnosis. Considering the average age of the participants and the difficulty of the visuospatial 2-back task, it is predicted that the groups will not show a behavioral difference, but there will be a difference in the hemodynamic brain response, and this difference will be observed as an increase in the right PFC. In this section, the findings of the study are discussed in the light of previous studies in the literature.

When sociodemographic characteristics were examined, studies were generally conducted with groups in which individuals between the ages of 35-45 participated, some of the patient participants were treated with drugs in the past/currently using drugs, and the duration of education was equalized in years $(7,17,18,20-$ $22,35-39)$.

This research was conducted with equal groups according education norms, and the number of participants in the groups with low and high BDI scores was equal. Since the relationship between depression symptoms and WM in the young population is curious, the mean age is smaller than other studies in the literature (high BDI score mean $\pm s d=22.2 \pm 2.28$, BDI score low mean $\pm s d=23.9 \pm 3.04$ ). While some studies were conducted with only the patient group without a control group, some of them included 
both the patient and the control group. Our study also differs from some studies in the literature in that it includes a control group. Our study differs from most studies in the literature in that it was conducted with participants who were not diagnosed with depression and determined according to their BDI scores.

Tasks used to measure WM are generally n-back $(7,19,22,35,38,40)$ and verbal fluency tests $(17,18,21$, $37)$, but different experiments $(20,36,39)$ are available.

In this study, a structured n-back task was designed on the visuospatial component of WM. It was expected that the participants would keep in mind the place of the stimulus that came out 2 before the stimulus they saw and decide whether it should be in the same place with the stimulus they saw by making a comparison. While designing this task, the stimuli used in the experiment were divided into emotional and neutral to see whether the behavioral performance and the brain hemodynamic response of the participants with a high BDI score differed when an emotional stimulus was present. The fact that the locations of the stimuli are kept in the mind and manipulated during the experiment is a cognitive task that serves the visual spatial sketchpad component of Baddeley and Hitch's memory model. In addition, the visuospatial n-back task is a unique paradigm in that it consists of both verbal and visual stimuli and allows measuring emotional and neutral stimuli together.

While some of the studies reported that there were behavioral differences between MDD and healthy control groups during the WM task, some found no difference. The inconsistent results of different studies with similar years of education show that a consensus cannot be reached in the literature. In this study, no significant difference was observed between the two groups in behavioral data. The reason for this is thought to be that the sample is from the young population. Even if the BDI score is high, the participants performed the same as the healthy group. Emotional stimuli also did not have a negative effect on the performance of the group with a high BDI score. The reason for this brings to mind the idea that emotional stimuli are not stimulating enough. When we ignore group and condition differences, right VLPFC activity appears to be increased in the visuospatial WM task. On the other hand, it was observed that the group with high depression scores showed increased activation during the WM task and in the right DLPFC.

This research was carried out using the NIRS method, which has been used frequently in recent years and has come to the fore with its easy and fast applicability. Although it is similar to magnetic resonance imaging (MRI) in the principle of measuring hemodynamic activity, but it cannot reach the activation of subcortical brain regions. Due to the similarity with MRI, MRI and NIRS studies were emphasized while examining the literature for this research.

In line with the studies examined in the literature, it is seen that the findings of our study are compatible with some information, but also contradictory with some results. The reason for this may be the average age of the participants, as well as the fact that the groups with MDD received medical treatment, the variety of WM tasks used, the difference in the difficulty of these tasks, the difference in the number of participants in the groups and the higher average age compared to our study. In our study, even though they were not diagnosed with MDD, people with high scores on BDI showed the same performance as people with low scores, and increased oxyHb change was observed in the right PFC, especially in DLPFC. In line with this 
finding, it is observed that the group with depressive features exhibited more PFC activation to achieve the same success.

The findings in the literature state that there is a hemispheric asymmetry in depression, and this asymmetry is observed as either hypoactivation in the left PFC or hyperactivation in the right PFC. Our study also supports the theory of hyperactivation in the right PFC (41).

\section{Conclusion}

No behavioral difference was observed between the groups with low and high Depression scores during the WM task. This may be because the task was not difficult enough. According to fNIRS results, the group with high depression scores showed increased activation in the right MPFC and right DLPFC during the WM task. As a result, the group with high depression scores showed more PFC activation to achieve the same performance.

\section{Declarations}

\section{Contributions:}

EY and ÖV designed the study. ÖV collected the data. EY and ÖV processed the data and wrote the manuscript. EY helped with statistical analysis and revised the manuscript. All authors reviewed the paper and approved the final version to be published.

\section{Funding}

No support was received for this study.

\section{Author Information}

Erol Yıldırım and Özge Vural have contributed equally to this work.

\section{Conflict of interest}

All authors declare that they have no conflict of interest.

\section{Informed consent}

All participants were given written informed consents.

\section{Consent to publish}

All authors consent to publication of the work.

\section{Conflict of Interest Statement}


The authors declare that the research was conducted in the absence of any commercial or financial relationships that could be construed as a potential conflict of interest.

\section{Ethics Approval}

This study was approved by the ethics committee of Istanbul Medipol University non-interventional clinical research.

* This study was produced from the master's thesis titled "The Relationship Between Brain Hemodynamic Response During the Working Memory Task and The Depression Score" prepared by the first author under the supervision of the second author.

1) Program of Neuroscience, Institute of Health Sciences, Istanbul Medipol University, Turkey.

ORCID: 0000-0003-1932-960X

2) Department of Psychology, Faculty of Humanities and Social Sciences, Istanbul Medipol University, Turkey.

ORCID: 0000-0002-0575-7278

3) Regenerative and Restorative Medical Research Center, Istanbul Medipol University, Istanbul, Turkey

\section{References}

1. Akiyama, T., Koeda, M., Okubo, Y., \& Kimura, M. (2018). Hypofunction of left dorsolateral prefrontal cortex in depression during verbal fluency task: A multi-channel near-infrared spectroscopy study. Journal of Affective Disorders, 231, 83-90. https://doi.org/10.1016/j.jad.2018.01.010

2. American Psychiatric Association. (2013). Diagnostic and statistical manual of mental disorders: DSM5 (5th ed.). Washington D.C.: American Psychiatric Association

3. Baker, J. M., Bruno, J. L., Gundran, A., Hosseini, S. M. H., \& Reiss, A. L. (2018). Fnırs measurement of cortical activation and functional connectivity during a visuospatial working memory task. PloS One, 13(8), e0201486. https://doi.org/10.1371/journal.pone.0201486

4. Baune, B. T., Miller, R., McAfoose, J., Johnson, M., Quirk, F., \& Mitchell, D. (2010). The role of cognitive impairment in general functioning in major depression. Psychiatry Research, 176(2-3), 183-189. https://doi.org/10.1016/j.psychres.2008.12.001

5. Daniel Lundqvist, A., \& Flykt (1998). Arne Öhman The Karolinska Directed Emotional Faces (KDEF)1998

6. Drevets, W. C. (2000). Neuroimaging studies of mood disorders. Biological Psychiatry, 48(8), 813-829. https://doi.org/10.1016/S0006-3223(00)01020-9

7. Edward, E., Smith, Stephaen, M., \& Kosslyn (Eds.). (2013). Cognitive Psychology: Pearson new international edition: Mind and brain. 
8. Evans, V. C., Iverson, G. L., Yatham, L. N., \& Lam, R. W. (2014). The relationship between neurocognitive and psychosocial functioning in major depressive disorder: A systematic review. The Journal of Clinical Psychiatry, 75(12), 1359-1370. https://doi.org/10.4088/JCP.13r08939

9. Fatmagül, H., \& Çiçek, H. (2016). 'Major Depresif Bozukluk' Tanımı, Etyolojisi ve Epidemiyolojisi: Bir Gözden Geçirme. Journal of Contemporary Medicine, 6(1), 51-66

10. Fitzgerald, P. B., Maller, J. J., Hoy, K. E., Thomson, R., \& Daskalakis, Z. J. (2009). Exploring the optimal site for the localization of dorsolateral prefrontal cortex in brain stimulation experiments. Brain Stimulation, 2(4), 234-237. https://doi.org/10.1016/j.brs.2009.03.002

11. Fletcher, P. C., \& Henson, R. N. (2001). Frontal lobes and human memory: Insights from functional neuroimaging. Brain: A Journal of Neurology, 124(Pt 5), 849-881.

https://doi.org/10.1093/brain/124.5.849

12. Golby, A. J., Poldrack, R. A., Brewer, J. B., Spencer, D., Desmond, J. E., Aron, A. P., \& Gabrieli, J. D. (2001). Material-specific lateralization in the medial temporal lobe and prefrontal cortex during memory encoding. Brain: A Journal of Neurology, 124(Pt 9), 1841-1854.

https://doi.org/10.1093/brain/124.9.1841

13. Hampson, M., Driesen, N. R., Skudlarski, P., Gore, J. C., \& Constable, R. T. (2006). Brain connectivity related to working memory performance. The Journal of Neuroscience: The Official Journal of the Society for Neuroscience, 26(51), 13338-13343. https://doi.org/10.1523/JNEUROSCI.3408-06.2006

14. Harvey, P. O., Fossati, P., Pochon, J. B., Levy, R., Lebastard, G., Lehéricy, S., \& Dubois, B. (2005). Cognitive control and brain resources in major depression: An fMRI study using the n-back task. Neurolmage, 26(3), 860-869. https://doi.org/10.1016/j.neuroimage.2005.02.048

15. Hirano, J., Takamiya, A., Yamagata, B., Hotta, S., Miyasaka, Y., Pu, S., \& Mimura, M. (2017). Frontal and temporal cortical functional recovery after electroconvulsive therapy for depression: A longitudinal functional near-infrared spectroscopy study. Journal of Psychiatric Research, 91, 26-35. https://doi.org/10.1016/j.jpsychires.2017.02.018

16. Hugdahl, K., Rund, B. R., Lund, A., Asbjørnsen, A., Egeland, J., Ersland, L., \& Thomsen, T. (2004). Brain activation measured with $\mathrm{fMRI}$ during a mental arithmetic task in schizophrenia and major depression. The American Journal of Psychiatry, 161(2), 286-293. https://doi.org/10.1176/appi.ajp.161.2.286

17. Jamovi [Computer software] (2021). : The jamovi project (2021). jamovi. (Version 1.8) [Computer Software]. Retrieved from https://www.jamovi.org

18. Kapucu, A., Kılıç, A., Özkılıç, Y., \& Sarıbaz, B. (2018). Turkish Emotional Word Norms for Arousal, Valence, and Discrete Emotion Categories. Psychological Reports, 1-22.

https://doi.org/10.1177/0033294118814722

19. Karakulak, E. Z. (2018). MULTIPL SKLEROZ HASTALARINDA KRONIK ÖZÜRLÜLÜK OLUŞTURAN SEMPTOMLAR ÜZERINDE TRANSKRANYAL DIREKT AKIMIN (TDCS) ETKILERININ ARAŞTIRILMASI. İstanbul: Sinir BilimDoktora

20. Kawano, M., Kanazawa, T., Kikuyama, H., Tsutsumi, A., Kinoshita, S., Kawabata, Y., \& Yoneda, H. (2016). Correlation between frontal lobe oxy-hemoglobin and severity of depression assessed using near- 
infrared spectroscopy. Journal of Affective Disorders, 205, 154-158.

https://doi.org/10.1016/j.jad.2016.07.013

21. Kelley, W. M., Miezin, F. M., McDermott, K. B., Buckner, R. L., Raichle, M. E., Cohen, N. J., \& Petersen, S. E. (1998). Hemispheric Specialization in Human Dorsal Frontal Cortex and Medial Temporal Lobe for Verbal and Nonverbal Memory Encoding. Neuron, 20(5), 927-936. https://doi.org/10.1016/S0896$6273(00) 80474-2$

22. KIRCHNER, W. K. (1958). Age differences in short-term retention of rapidly changing information. Journal of Experimental Psychology, 55(4), 352-358. https://doi.org/10.1037/h0043688

23. Kinou, M., Takizawa, R., Marumo, K., Kawasaki, S., Kawakubo, Y., Fukuda, M., \& Kasai, K. (2013). Differential spatiotemporal characteristics of the prefrontal hemodynamic response and their association with functional impairment in schizophrenia and major depression. Schizophrenia Research, 150(2-3), 459-467. https://doi.org/10.1016/j.schres.2013.08.026

24. Klojčnik, M., Kavcic, V., \& Bakracevic Vukman, K. (2017). Relationship of Depression With Executive Functions and Visuospatial Memory in Elderly. International Journal of Aging \& Human Development, 85(4), 490-503. https://doi.org/10.1177/0091415017712186

25. Kring, A. M., Davison, G. C., Neale, J. M., \& Johnson, S. L. (2007). Abnormal psychology.

26. Lee, R. S. C., Hermens, D. F., Porter, M. A., \& Redoblado-Hodge, M. A. (2012). A meta-analysis of cognitive deficits in first-episode Major Depressive Disorder. Journal of Affective Disorders, 140(2), 113-124. https://doi.org/10.1016/j.jad.2011.10.023

27. Levin, R. L., Heller, W., Mohanty, A., Herrington, J. D., \& Miller, G. A. (2007). Cognitive Deficits in Depression and Functional Specificity of Regional Brain Activity. Cognitive Therapy and Research, 31(2), 211-233. https://doi.org/10.1007/s10608-007-9128-z

28. Liu, X., Sun, G., Zhang, X., Xu, B., Shen, C., Shi, L., \& Liu, P. (2014). Relationship between the prefrontal function and the severity of the emotional symptoms during a verbal fluency task in patients with major depressive disorder: A multi-channel NIRS study. Progress in Neuro-Psychopharmacology \& Biological Psychiatry, 54, 114-121. https://doi.org/10.1016/j.pnpbp.2014.05.005

29. Matsuo, K., Glahn, D. C., Peluso, M. A. M., Hatch, J. P., Monkul, E. S., Najt, P., \& Soares, J. C. (2007). Prefrontal hyperactivation during working memory task in untreated individuals with major depressive disorder. Molecular Psychiatry, 12(2), 158-166. https://doi.org/10.1038/sj.mp.4001894

30. Mohn, C., \& Rund, B. R. (2016). Neurocognitive profile in major depressive disorders: Relationship to symptom level and subjective memory complaints. BMC Psychiatry, 16, 108.

https://doi.org/10.1186/s12888-016-0815-8

31. Necla, \& Öner, \& W. Ayhan LeCompte (1983). Durum/uk-sürekli kaygı envanteri el kitabı. İstanbul:Boğaziçi Üniversitesi

32. Norbury, R., Godlewska, B., \& Cowen, P. J. (2014). When less is more: A functional magnetic resonance imaging study of verbal working memory in remitted depressed patients. Psychological Medicine, 44(6), 1197-1203. https://doi.org/10.1017/S0033291713001682

33. Nystrom, L. E., Braver, T. S., Sabb, F. W., Delgado, M. R., Noll, D. C., \& Cohen, J. D. (2000). Working memory for letters, shapes, and locations: Fmrı evidence against stimulus-based regional organization 
in human prefrontal cortex. Neurolmage, 11(5 Pt 1), 424-446.

https://doi.org/10.1006/nimg.2000.0572

34. Okada, G., Okamoto, Y., Morinobu, S., Yamawaki, S., \& Yokota, N. (2003). Attenuated left prefrontal activation during a verbal fluency task in patients with depression. Neuropsychobiology, 47(1), 21-26. https://doi.org/10.1159/000068871

35. Okamoto, M., Dan, H., Sakamoto, K., Takeo, K., Shimizu, K., Kohno, S., \& Dan, I. (2004). Threedimensional probabilistic anatomical cranio-cerebral correlation via the international 10-20 system oriented for transcranial functional brain mapping. Neurolmage, 21(1), 99-111.

https://doi.org/10.1016/j.neuroimage.2003.08.026

36. Psychology Software Tools. E-Prime (Version 2) [Computer software]. Pittsburgh, PA

37. Savitz, J., \& Drevets, W. C. (2009). Bipolar and major depressive disorder: Neuroimaging the developmental-degenerative divide. Neuroscience and Biobehavioral Reviews, 33(5), 699-771. https://doi.org/10.1016/j.neubiorev.2009.01.004

38. Schecklmann, M., Dresler, T., Beck, S., Jay, J. T., Febres, R., Haeusler, J., \& Fallgatter, A. J. (2011). Reduced prefrontal oxygenation during object and spatial visual working memory in unpolar and bipolar depression. Psychiatry Research, 194(3), 378-384.

https://doi.org/10.1016/j.pscychresns.2011.01.016

39. Sheremata, S. L., Bettencourt, K. C., \& Somers, D. C. (2010). Hemispheric asymmetry in visuotopic posterior parietal cortex emerges with visual short-term memory load. The Journal of Neuroscience: The Official Journal of the Society for Neuroscience, 30(38), 12581-12588.

https://doi.org/10.1523/JNEUROSCI.2689-10.2010

40. Soveri, A., Antfolk, J., Karlsson, L., Salo, B., \& Laine, M. (2017). Working memory training revisited: A multi-level meta-analysis of n-back training studies. Psychonomic Bulletin \& Review, 24(4), 10771096. https://doi.org/10.3758/s13423-016-1217-0

41. Spielberger, C. D., Gorsuch, R. L., Lushene, R., Vagg, P. R., \& Jacobs, G. A. (1983). Manual for the StateTrait Anxiety Inventory. Palo Alto, CA: Consulting Psychologists Press

42. Şahin Hisli, N., Batıgün, D., A., \& Uğurtaş, S. (2002). Kısa Semptom Envanteri (KSE): Ergenler İçin Kullanımının Geçerlik, Güvenilirlik ve Faktör Yapısı. Türk Psikiyatri Dergisi, 13(2), 125-135

43. Thibodeau, R., Jorgensen, R. S., \& Kim, S. (2006). Depression, anxiety, and resting frontal EEG asymmetry: A meta-analytic review. Journal of Abnormal Psychology, 115(4), 715-729. https://doi.org/10.1037/0021-843X.115.4.715

44. Vermeij, A., van Beek, A. H. E. A., Reijs, B. L. R., Claassen, J. A. H. R., \& Kessels, R. P. C. (2014). An exploratory study of the effects of spatial working-memory load on prefrontal activation in low- and high-performing elderly. Frontiers in Aging Neuroscience, 6, 303.

https://doi.org/10.3389/fnagi.2014.00303

45. Wagner, A. D., Desmond, J. E., Glover, G. H., \& Gabrieli, J. D. (1998). Prefrontal cortex and recognition memory. Functional-MRI evidence for context-dependent retrieval processes. Brain: A Journal of Neurology, 121 (Pt(10), 1985-2002. https://doi.org/10.1093/brain/121.10.1985 
46. Wagner, G., Sinsel, E., Sobanski, T., Köhler, S., Marinou, V., Mentzel, H. J., \& Schlösser, R. G. M. (2006). Cortical inefficiency in patients with unipolar depression: An event-related FMRI study with the Stroop task. Biological Psychiatry, 59(10), 958-965. https://doi.org/10.1016/j.biopsych.2005.10.025

47. Yüksel, D., Dietsche, B., Konrad, C., Dannlowski, U., Kircher, T., \& Krug, A. (2018). Neural correlates of working memory in first episode and recurrent depression: An fMRI study. Progress in NeuroPsychopharmacology \& Biological Psychiatry, 84, 39-49.

https://doi.org/10.1016/j.pnpbp.2018.02.003

48. Zaninotto, L., Guglielmo, R., Calati, R., loime, L., Camardese, G., Janiri, L., \& Serretti, A. (2015). Cognitive markers of psychotic unipolar depression: A meta-analytic study. Journal of Affective Disorders, 174, 580-588. https://doi.org/10.1016/j.jad.2014.11.027

49. Zhu, Y., Quan, W., Wang, H., Ma, Y., Yan, J., Zhang, H., \& Yu, X. (2018). Prefrontal activation during a working memory task differs between patients with unipolar and bipolar depression: A preliminary exploratory study. Journal of Affective Disorders, 225, 64-70.

https://doi.org/10.1016/j.jad.2017.07.031

\section{Figures}

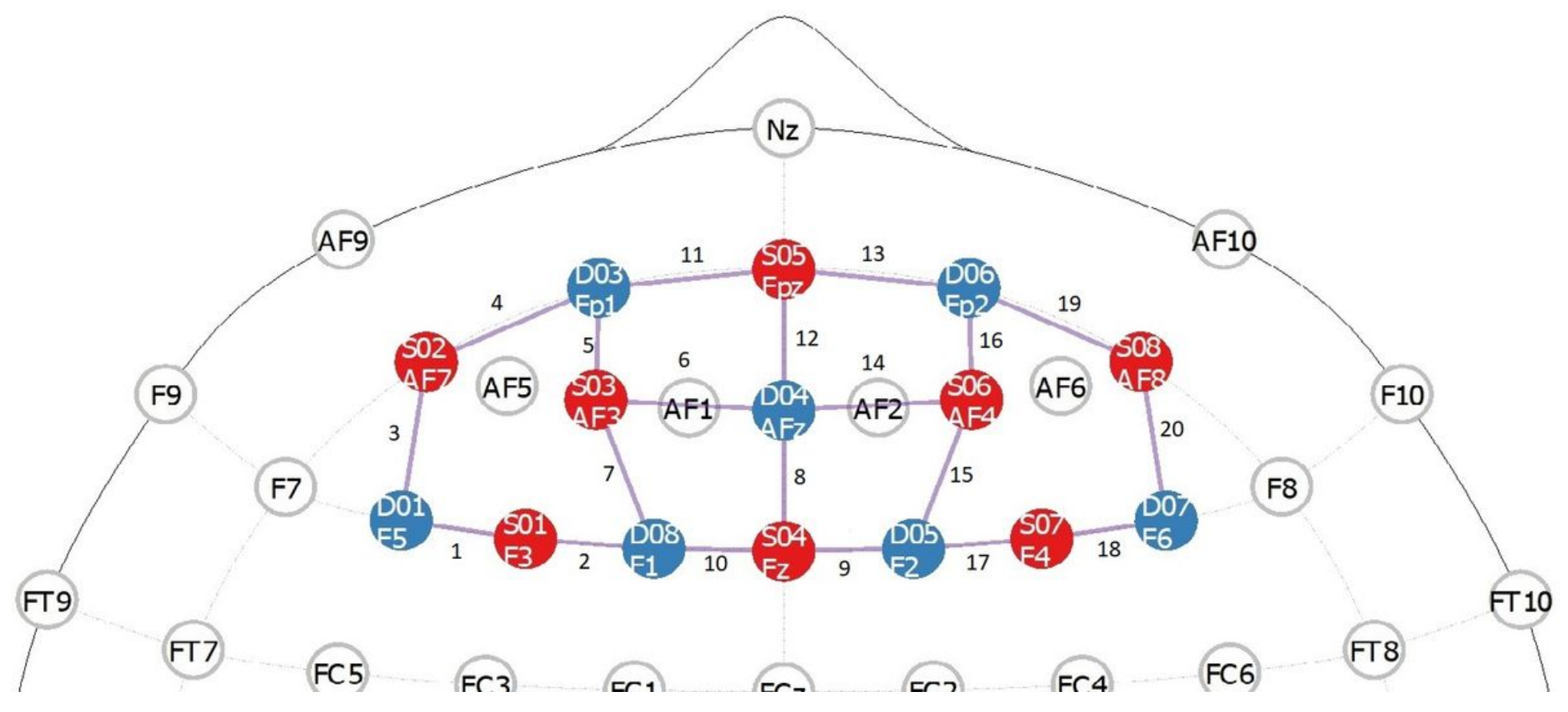

Figure 1

Layout of source, detector and channels. 


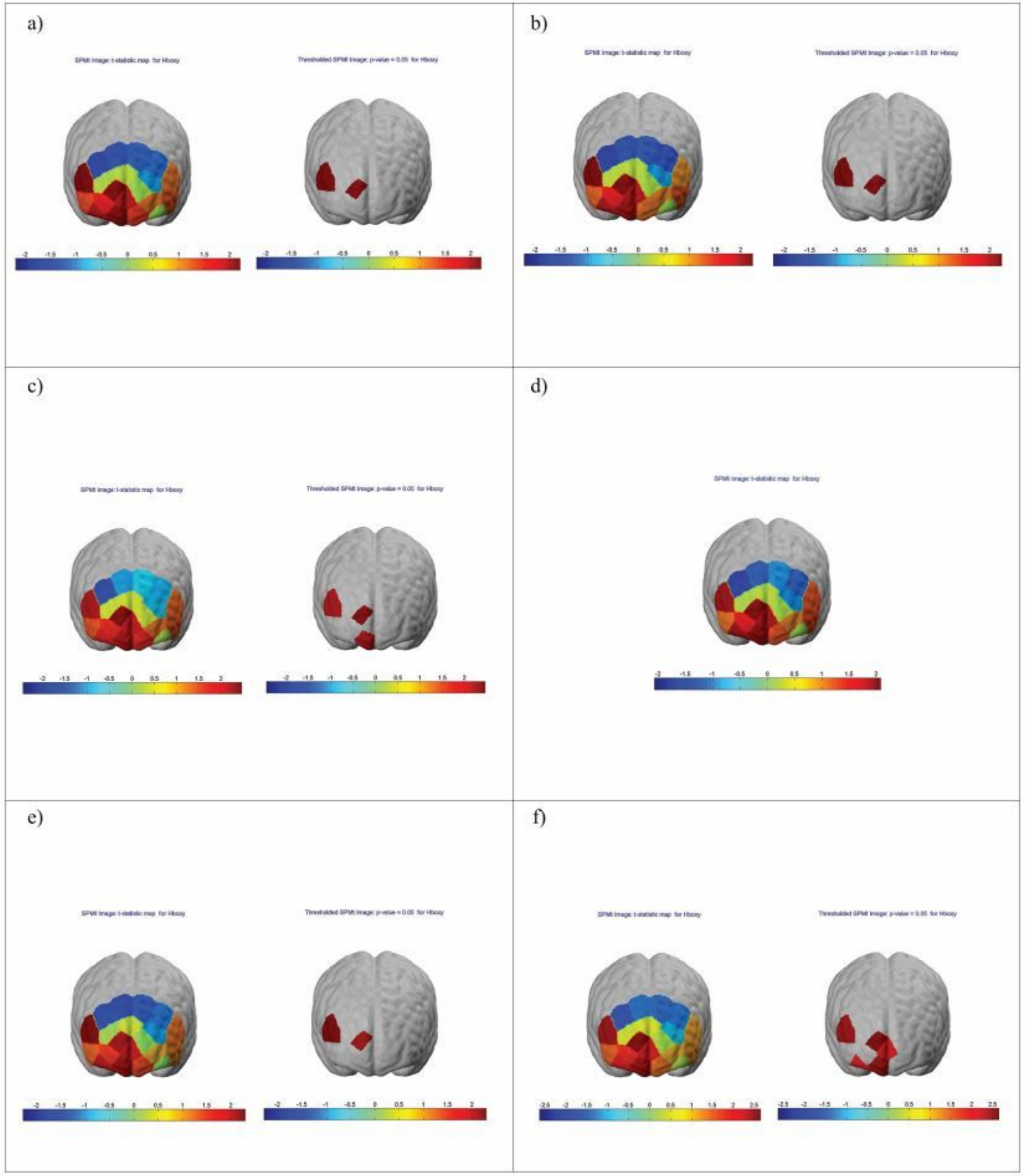

\section{Figure 2}

The hemodynamic brain activities during the working memory task. a) Emotional stimuli condition (left: activation of all channels, right: channels where difference is significant). b) Neutral stimuli condition (left: activation of all channels, right: channels where difference is significant). c) Emotional face condition (left: activation of all channels, right: channels where difference is significant) d) Neutral face condition (activation of all channels). e) Emotional word condition (left: activation of all channels, right: channels 
where difference is significant). f) Emotional word condition (left: activation of all channels, right: channels where difference is significant). 